Short Research Article

\title{
A Comparative Study on Presence of Heavy Metals Lead and Cadmium in Tomato Ketchups used by Street Vendors of Delhi NCR
}

\author{
Vaishali', $\underline{\text { Srishti Negi }}{ }^{2}$
}

${ }^{1}$ M.Sc. Student, ${ }^{2}$ Assistant Professor, Department of Nutrition and Dietetics, Faculty of Allied Health Sciences, Manav Rachna International Institute of Research \& Studies, Faridabad, Haryana, India.

DOI: https://doi.org/10.24321/2394.6539.202007

\section{I $\quad \mathbf{N} \quad \mathbf{F} \quad \mathbf{O}$}

\section{Corresponding Author:}

Vaishali Verma, Department of Nutrition and Dietetics, Faculty of Allied Health Sciences, Manav Rachna International Institute of Research \& Studies, Faridabad, Haryana, India. E-mail Id:

vaishaliverma21@gmail.com

Orcid Id:

https://orcid.org/0000-0001-7001-1942

How to cite this article:

Vaishali, Negi S. A Comparative Study on Presence of Heavy Metals Lead and Cadmium in Tomato Ketchups used by Street Vendors of Delhi NCR. J Adv Res Med Sci Tech 2020; 7(2): 15-18.

Date of Submission: 2020-05-25

Date of Acceptance: 2020-06-26

\section{$\begin{array}{llllllll}\mathbf{A} & \mathbf{B} & \mathbf{S} & \mathbf{T} & \mathbf{R} & \mathbf{A} & \mathbf{C} & \mathbf{T}\end{array}$}

Background: From past few years food safety has emerged as public health issue and has diverted attention of researchers towards health hazard associated with food contamination. Food contamination is a major concern of street food industry serving as a source of food to people. Tomato ketchup is consumed by all age groups along numerous products, sold by street vendors. Tomatoes are preserved in the form of ketchups.

Methodology: A total of 12 samples were collected, 3 each from Delhi, Noida, Gurugram, Faridabad respectively. The procured samples were then analysed for the presence of heavy metals lead and cadmium using Atomic Absorption Spectrophotometer (AAS).

Result: The mean concentration of cadmium in all samples was Below Detectable Limit (BDL).Whereas, mean concentration of lead was highest in the regions of Delhi i.e., $0.183 p p m$ followed by regions of Noida $(0.096 \mathrm{ppm})$, Faridabad (0.089ppm) and Gurugram (0.031 ppm).

Conclusion: The cadmium concentration in samples were below permissible limit whereas mean concentration of samples in region of Delhi, Faridabad and Noida exceeded the levels set by WHO/ FAO joint committee. So, excess or prolong consumption may cause toxicity or health hazards.

Keywords: Food Contamination, Tomato ketchup, Street Vendors, Heavy Metals, Atomic Absorption Spectrophotometer (AAS).

\section{Introduction}

Street food industry feeds million of people in developing countries by selling off the produce at very affordable rates and is easily assessable by each group of society but the hygiene and sanitation is a major concern of food safety. ${ }^{1}$ Street food serves as major source of nutrition for urban poor and lower middle class and due to hygiene condition is considered to be major public health risk. ${ }^{2}$ In developing countries like India these vendors do not acquire skills in form of formal education but form of family business. ${ }^{3}$ Due to increase trend of street food industry and fast food there is growing demand of tomato ketchup served along various types of foods. ${ }^{4}$ Tomato ketchup is a condiment 
made primarily from tomato rich in vitamin C, provitamin A, Potassium, Lycopene: which provide various health benefits like protection against cardiovascular diseases, cancer and other diseases. ${ }^{5}$ Consumption of tomato and its processed product increase plasma Lycopene concentration. ${ }^{6}$ When dealing with Street food industry food safety emerge as an important matter of concern. Food safety always deals with food safe from any kind of contamination. Food contamination can happen at any stage from process of production to transportation, storage, sales and cooking procedure. ${ }^{7}$ Heavy metal contamination has been often reported in various types of food products. Industrial and agricultural practices have caused widespread dispersion and increased load of metal in food chain which cannot be easily eliminated. Heavy metals Arsenic, lead, cadmium and mercury are of particular concern because of their toxicity. ${ }^{8}$

The toxicity of heavy metals is regulated by the source, method and time period of exposure. Ingestion of contaminated food is one of the common sources of contamination along exposure to skin and inhalation. ${ }^{9}$

Cadmium and lead when enter human body gets accumulated. Exposure of cadmium leads to "renal dysfunction, lung diseases, and defects in bones like osteomalacia, osteoporosis and cardiovascular diseases". On other hand lead exposure leads to poisoning as it inhibits synthesis of haemoglobin along this it effects renal, reproductive and cardiovascular functioning. Lead poisoning also damages central and peripheral nervous system, damage of gastrointestinal and urinary tract. ${ }^{10}$

Absorption of heavy metal lead is enhanced in body when there are calcium and zinc deficiencies. ${ }^{10}$ Adults take "10\%$15 \%$ " of lead through gastrointestinal tract and children's uptake up to "50\%" and crosses blood-brain barrier therefore children's are more vulnerable to lead toxicity as compared to adults. ${ }^{11}$ Whereas absorption of cadmium is more through pulmonary absorption. ${ }^{12}$

Heavy metals enter the human body or food cycle either by consumption of non-vegetarian produce or by consumption of plant sources which uptake these elements from soil. ${ }^{13}$
There is very limited information available on heavy metals content in tomato ketchup, In this study the level of lead and cadmium in tomato ketchup used by street food vendors are reported and compared on the basis of region.

\section{Material And Method}

The study was conducted in different region of Delhi NCR. Twelve places ( 3 from each region) were selected from different zones of Faridabad, Gurgaon, Delhi and Noida. Sample was collected from each selected place.

The Samples were randomly collected in sterilised air sealed glass containers from street vendors. The collected samples were transported in ambient conditions to the test lab as soon as they were collected (within time frame of 2 days) for estimation of heavy metals i.e. lead and cadmium. All requisite precautions were taken to avoid any kind of contamination of samples.

The presence of heavy metals residue in tomato ketchup was done using Atomic Absorption Spectrophotometer (AAS). Atomic Absorption Spectrophotometer is a "spectro analytical procedure for quantitative determination of chemical elements".

The collected measurements and data was processed statistically and represented in mean \pm standard deviation. For the significance of difference ANOVA was applied in Microsoft Excel.

\section{Results}

The mean concentrations of heavy metals lead and cadmium in samples collected from street food vendors represented in Table 1 and Table 2.

The highest mean concentration of lead was found in Delhi 0.183 ppm followed by Noida 0.096 ppm, Faridabad $0.089 \mathrm{ppm}$ and Gurugram $0.031 \mathrm{ppm}$. The levels of concentration of heavy metal Lead in different sites of a locale did not show significant difference $(P>0.05)$.

The levels of cadmium in all samples were below detectable limit.

Table I.Lead concentration in samples

\begin{tabular}{|c|c|c|c|c|c|}
\hline Metal & Locale & Minimum & Maximum & Mean \pm SD & P-value \\
\hline \multirow{4}{*}{ Lead (ppm) } & Delhi & 0.1 & 0.311 & $0.183 \pm 0.11$ & \multirow{4}{*}{0.42} \\
\hline & Gurugram & $\mathrm{BDL}$ & 0.093 & $0.031 \pm 0.05$ & \\
\hline & Faridabad & BDL & 0.266 & $0.089 \pm 0.15$ & \\
\hline & Noida & $\mathrm{BDL}$ & 0.148 & $0.096 \pm 0.08$ & \\
\hline \multicolumn{6}{|c|}{ BDL: Below Detectable Limit } \\
\hline \multicolumn{6}{|c|}{ SD: Standard Deviation } \\
\hline \multicolumn{6}{|c|}{ Method: Anova } \\
\hline
\end{tabular}


Table 2.Cadmium concentration in samples

\begin{tabular}{|c|c|c|}
\hline Metal & Locale & Mean \pm SD \\
\hline \multirow{4}{*}{ Cadmium } & Delhi & BDL \\
\cline { 2 - 3 } & Gurugram & BDL \\
\cline { 2 - 3 } & Faridabad & BDL \\
\cline { 2 - 3 } & \multicolumn{2}{|c|}{ Noida } \\
\hline \multicolumn{2}{|c|}{ BDW: Below Detectable Level } \\
\hline \multicolumn{2}{|c|}{ SD: Standard Deviation } \\
\hline
\end{tabular}

The mean concentration of Lead in regions of Delhi, Noida and Faridabad exceeded the maximum limit set by WHO/ FAO joint Codex alimentarious commission i.e. 0.05 ppm as represented in Figure 1.

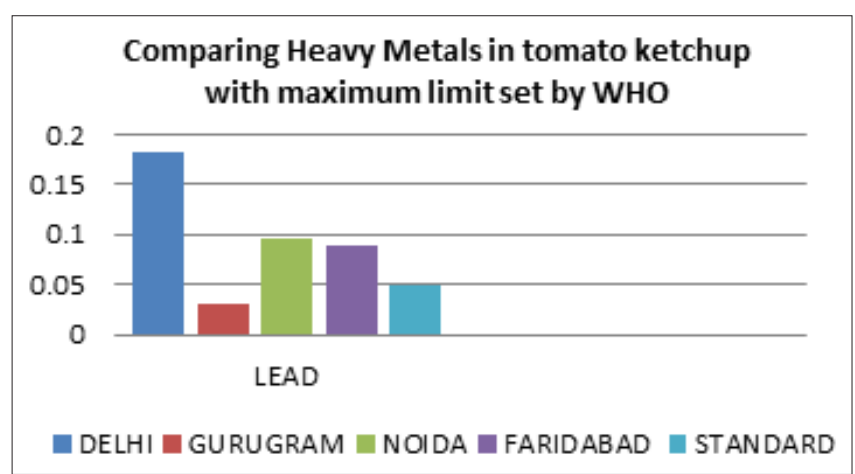

Figure I.Comparison of Lead concentration with maximum limit set by FAO/WHO

\section{Discussions}

The concentration of heavy metal lead collected from different sites of Delhi NCR Region analysed using one way ANOVA depicting that concentration of heavy metals in ketchup collected show minor variations but do not differ significantly. Whereas the cadmium content in all regions were below detectable limit.

The cadmium content in all the samples of tomato ketchup was lower than the maximum level, but Samples of Delhi, Noida and Faridabad exceeded the maximum limits of heavy metal lead set by WHO/FAO Joint codex alimentarious Committee. ${ }^{14,15,16}$ As per sixteenth joint committee held by WHO and FAO weekly consumption of lead should not exceed $0.05 \mathrm{mg} / \mathrm{kg}$ body weight and $0.075 \mathrm{mg} / \mathrm{kg}$ body weight for cadmium per week from all sources. ${ }^{15,17}$

The most endangered and vulnerable category is poor as they are more dependent on cheap sources of food especially in developing countries which rises as a major public concern. ${ }^{18}$

\section{Novel Observation}

The heavy metal contamination of food can occur at any point and cumulative toxins can affect children's at the most. There are various consumer reports that depict branded tomato ketchups being served in India contain heavy metal lead at detection limit $0.1 \mathrm{mg} / \mathrm{kg}$ limit but even small amount for over a long period consumption can be harmful. ${ }^{19}$ Along this here we found out that the presence of heavy metal lead exceeds the maximum limit set by FAO/ WHO which is a major concern of public health as even small quantity of lead can be toxic especially in children and other vulnerable section of society.

\section{Strenth of the Study}

The present study focuses on heavy metal concentration in tomato ketchup used by street food vendors. Street food Industry is one of the largest informal jobs creating industry in developing countries like India and a major source of nutrition for urban poor. The heavy metal contamination is one of the form of contaminants that in now time everyone is consuming because of environmental dispersion and can be toxic even in small quantity especially to vulnerable group like children. Here we have focused on Tomato Ketchup as it is a type of condiment being served with almost all kind of street foods and consumed by all age groups.

\section{Weakness of Study}

The focus of study is only on one type of food being served by street vendors. There are chances if included other category of food groups the population is consuming high level toxic heavy metals. These metals not only enter body through food chain but also through skin and respiratory tract.

\section{Conclusion}

Heavy metal contamination is of major concern as they do not decompose and can cause toxicity even in small quantity.

The results of study concluded that tomato ketchup shows the presence of heavy metal lead in region of Delhi, Noida and Faridabad exceed maximum limit set by WHO i.e. $0.05 \mathrm{mg} / \mathrm{kg}^{15}$ which is a major public health concern. According to WHO tolerable intake value of lead is $0.05 \mathrm{mg} /$ $\mathrm{kg}$ bodyweight/week from all sources, excess or prolong consumption may be toxic and hazardous to health which can be acute like gastrointestinal disturbances, hepatic damage and chronic which generally include haematological effects. $^{20}$

\section{Ethical Declarations}

Originality: The manuscript is an original work and do not include any tables or figures from other works.

Authorship: All authors have equally contributed.

Conflict of Interest: There is no conflict of interest between authors and the project is self funded project. 
Fundamental Errors: Authors are obliged to notify about errors at any point immediately.

\section{Conflict of Interest: None}

\section{References}

1. Nicollas B, Razzack BA. Street vended food improvements: critical review, Pakistan. journal of nutrition 2007.

2. Project clean food. FSSAI. 2011.

3. Pilz M, Uma G, Venkatram R. Skills development in Informal sector in India: The case of street food vendors. International Review of Education 2015.

4. Bhisey R. Tomato ketchup market- An insight into the important factors and trends influencing market by 2024, Transparency Market research. 2016.

5. Linnemann AR, Benner. An explorative study on the systematic development of tomato ketchup with potential health benefits using the chain information model. Trends in food science and technology 2017; 18.

6. Nasir MU, Hussain S, Jabbar S. Tomato processing, lycopene and health benefits: A Review. Science letters 2015; 3.

7. Mihai A, Holban AM. Modern biological approaches to improve human health, food safety and preservation, Academic Press. 2018.

8. duruibe JO, Ogwuebu MO. Heavy metal pollution and human biotoxic effects. International journal of physical sciences 2007; 2.

9. Ajah KC, Ademiluyi J, Nnaji CC. Spatiality, seasonality and ecological risks of heavy metals in vicinity of a degenerate Municipal Central dumpsite in Enugu, Nigeria. Journal of environmental health sciences and engineering 2015.

10. Metals and your food, Chemicals, metals \& pesticides in food (2019). FDA.

11. Jarup L. Hazards of heavy metal contamination. British medical bulletin 2003; 68(1).

12. Joint FAO/WHO Food Standard Programme Codex Committee on Contaminants in Food (2011), FAO/WHO.

13. Brassica Junicca L. Heavy metal toxicity: effect on plant growth, biochemical parameters and metal accumulation. International journal of plant production 2009; 3.

14. Food safety and standard contamination, toxin and residue regulation, FSSAI. 2011.

15. REP/18,Codex general standard for contaminants and toxins in food and feed, FAO. 2018.

16. Zein H. Food safety management system Implementation in manufacturing of tomato concentrates and evaluation of certain contaminants in final products. Middle East journal of applied sciences 2018; 8(4).

17. Aparna, Chauhan AK, Singh PK. Estimation of toxic, trace and essential metals ( $\mathrm{Pb}, \mathrm{Cd}, \mathrm{Fe}, \mathrm{Zn}, \mathrm{Mn}, \mathrm{Cu}, \mathrm{Mg}, \mathrm{K}$ ) in fruit and vegetable products (Jam, Ketchup, Pickles) by Atomic Absorption Spectrophotometer. 2018.

18. Hoha GV, Costachescu E, Leahu A, Pasarin B. Heavy metals contamination levels in processed meat marketed in Romania. Environment Engineering and Management Journa 2014.

19. Tomato Ketchup: which is best for you? Consumer voice Report. 2018.

20. Exposure to lead: A major public health concern (2010), (2014), WHO. 